\title{
Machine Performance Standard Provides Opportunity to Improve Quality and Productivity
}

C. D. Lovett

U.S. DEPARTMENT OF COMMERCE Technology Administration National Institute of Standards and Technology

Gaithersburg, MD 20899

QC

100

.456

N0.5775

1995 



\section{Machine Performance Standard Provides Opportunity to Improve Quality and Productivity}

\section{D. Lovett}

U.S. DEPARTMENT OF COMMERCE Technology Administration National Institute of Standards and Technology

Gaithersburg, MD 20899

December 1995

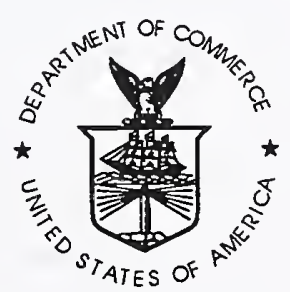

U.S. DEPARTMENT OF COMMERCE Ronald $H$. Brown, Secretary

TECHNOLOGY ADMINISTRATION Mary L. Good, Under Secretary for Technology NATIONAL INSTITUTE OF STANDARDS AND TECHNOLOGY

Arati Prabhakar, Director 



\section{Machine Performance Standard Provides Opportunity to Improve Quality and Productivity}

Do manufacturers know the machining capabilities and limitations of their machine tools ?

Manufacturing capability is a lifelong concern. It starts when preparing the specifications and the acceptance test for the purchase of a new machine, and it should continue throughout the service life of the machine. Money is an important factor in deciding which machine to buy. However, investing in an inferior machine that won't do the job according to expectations can become an impediment to quality and productivity, and thus a very expensive purchase for the firm [1]. A bad selection process can lead to exceptionally high maintenance and operating costs. The ANSI/ASME B5.54 standard provides a means to improve the selection process by providing standardized test procedures and common terminology. When it is used appropriately, this standard will result in the purchasing of the proper machine to match the job. This will optimize the results at the company's bottom line, which is important to all firms, regardless of the size of their operations.

Many manufacturers can improve productivity and quality by implementing strategies that will allow them to gain more control of their manufacturing process. Evaluating and documenting the capabilities/limitations of machines are important steps toward more effective control over the manufacturing process. Without adequate knowledge of the capabilities of machining/turning centers to machine a work piece to a specified tolerance, at a given feed rate, subjected to various temperature profiles, it is difficult to implement adequate control to assure against out-of tolerance conditions. This may lead to rejecting or sometimes reworking machined parts. After all, if you cannot measure what is going on in the process, you cannot control it. In order to make meaningful evaluation of machine tool performance, a performance standard such as the ASME B5.54-1992 is essential. This standard specifies what should be measured, how to measure and suggests instrumentation for making the measurements.

Does the high cost of machine tools and the high value of the products produced by the machine tools justify a more formal \& scientific-based infrastructure for performing an ongoing assessment of the machining performance of machine tools?

Industry has invested billions of dollars in machine tools, and industry continues to add approximately four to five billion dollars of new investment each year [2]. A large portion of this new investment is for machining centers and turning centers. In a multi-machine manufacturing system, each machine adds significant value to the parts. Over the life of the machine, the value added to the cumulative parts may be several orders of magnitude greater than the value invested in the machining centers or turning centers. In addition to the machines, there are large amounts of investment associated with installation and support of these machines. The totals for all of these costs and capital investments are staggeringly large. The mention of these costs builds a case for a more structured approach for measuring and tracking the performance of machining centers and turning centers over the useful life of these machines. Some companies spend an orders of magnitude more on inspecting the product than performing the basic metrology for 
ensuring the integrity of the machine that is making the product. The objective is not just to spend more because little has been spent in this area in the past. But rather, the objective is to allocate funds to this area because there have been significant technological innovations which make a high probability of significant returns on monies invested. Also, investment in this area opens a window of opportunity for improving the basic understanding of some of the systematic variations that occur in the machining process. As more data from monitoring is obtained and a better understanding of the fundamentals of the manufacturing process is developed, this information can be organized into a continually improving knowledge-base of the manufacturing processes performed by machining centers and turning centers.

\section{Do manufacturers know about the available technology that will allow them to store and retrieve machine performance data?}

Today's advances in information technology, instrumentation, and computer computational power as well as cost trends for sensors, suggest that an ongoing program of manufacturingprocess monitoring is both technically feasible and probably economically justified. The technical and economic barriers of yesterday's technology only allowed one to get an overview of the manufacturing process. However, with today's instrumentation and information technology, there exist the necessary components for developing a monitoring system that "zooms" in for a close study of the several types of machining errors that actually affect machining capability . These machining errors are likely to be nonrepeatability, deviation between commanded position and actual position --or low accuracy, contouring errors, and imperfection in the spindle axis of rotation, to mention just a few. Some of these errors can be caused by temperature sources both internal to and external to the machine, while other errors may be caused by internal and external vibration sources .

Several different types of instruments can be used to measure these machining errors:

A. Laser interferometer. This is used for measuring the machine's positioning accuracy, angular accuracy, bi-directional repeatability, periodic error, and volumetric performance. The laser diagonal method is used for determining volumetric performance which gives an assessment of multi-axes machining performance .

B. Repeatability module. This consists of contact or non-contact probes for measuring the machine's repeatability; that is, measuring the machine's ability to repeatedly return to the same location. The non-contact probes are often capacitance probes.

C. Telescoping ballbar. This measures contouring performance. It is also a good diagnostic tool for indicating source of errors, servo adjustments, loose gibs, and non squareness of the machine's axes.

D. Spindle error analyzer. This measures various spindle errors, describing how the actual spindle axis of rotation deviates from the perfect axis of rotation. Spindle 
errors can cause poor surface finish, dimensional errors, and errors in part form.

E. Compliance module. This measures the machine's deformation under load. It gives an indication of lack of rigidity and the lack of rigidity can cause dimensional errors, poor surface finish, and the inability of the machine to effectively use its rated horsepower.

F. Spindle thermal analyzer. This analyzes the deformation of the spindle axis in five degrees-of-freedom, due to thermal expansion.

Some of these are new instruments that entered the marketplace either during the development of the B5.54 standard or soon after it was published in 1992. Most of these instruments have automatic data acquisition which significantly reduces the amount of work in acquiring data during testing. Generating various types of plots has been made relatively easy with the use of software and data acquisition systems. Storage and retrieval of plots and data make it easy to perform comparisons of previously stored plots, and, therefore, facilitating the trending of key performance parameters. Software is now available which transfers machining performance data to spread sheets. This allows one to tap the enhanced computational capabilities and trending analysis of the spread sheets.

\section{Can trending of the key machining performance data serve as some of the documentation needed for quality programs such as ISO 9000 and the Malcolm Baldrige Award?}

National performance standards for machine tools can provide a window of opportunity to implement procedures for improving quality of the machined products. If these procedures are properly documented, they can provide a valid audit trial for quality programs such as ISO 9000 , or the ANSI/ASQC Q 90 series. They can also be used to demonstrate conformance to guidelines given in AMT's Management Handbook for Quality Systems Development[3]. AMT is the Association for Manufacturing Technology, which is the U.S. machine tool trade association.

A precursor to the wise and effective use of machine tools is knowing the capabilities of the machine tools and implementing controls to ensure that the machines are not used for jobs that exceed their capabilities. This will require a three-step process: (1) identifying the pertinent process variables, (2) measuring these variables, and (3) establishing upper and lower limits on the process variables that correspond to the part design tolerance band that you want to achieve. This last item is not an easy task. This concept would require more statistical process control (SPC) on the machining process and would possibly lead to less SPC on the parts, thus saving on the cost of inspection. One approach to implementing SPC on the process is to periodically make performance measurements as specified in the B5.54 and develop trends on the measured values.

AMT's handbook on quality and other quality certification organizations give guidelines for documenting a company's quality effort. For example, AMT's quality guidelines state that a manufacturing company should have in place sufficient controls to assure a quality product is 
being produced. This requires periodical calibrations of manufacturing equipment to make sure the equipment meets specification, documented evidence of calibrations and traceability of reference standards to national standards. Within the documentation the manufacturing methods and test methods should be clearly described to support the quality in the product. When quality problems are detected, there should be clearly defined responsibilities for follow-up including investigation and analysis of the cause of the problem, and implementing a procedure to prevent non-conformance from recurring. To implement corrective action for unacceptable machine performance requires improved diagnostic capabilities. These improved diagnostics should identify the physical adjustments to bring the machine's performance to acceptable levels.

Once a problem of nonconformance is detected, management becomes anxious to know the solutions. Finding solutions often requires improved diagnostic tools and greater accessibility to the information sources at the machine tool builders, and the "know-how" of independent service companies specializing in performance evaluations of machine tools. Access to remote knowledge sources can be provided via computers connected to MODEMs and phone lines or via INTERNET, supplying information flow in the form of text, graphics, photos, and recorded diagnostic sounds of the machines. This information flow can occur between manufacturing firms and technical providers of machine tool metrology.

You can purchase a copy of the ASME B5.54-1992 Standard from The American Society of Mechanical Engineerings' Publication Center, at 22 Law Drive, Fairfield NJ. 07007 ( 800843 2763). The title of this standard is "Methods for Performance Evaluation of Computer Numerically Controlled Machining Centers". For information on how to participate in the development of the a new national standard for turning centers, please write to C. Denver Lovett, Chairman of the Technical Committee 52 of the ASME B5 committee on machine tools, at NIST, Building 304, Room 142, Gaithersburg MD 20899, or send a fax at (301) 869-3750 or E-mail at lov@micf.nist.gov

References

1. Aderson J. , Lovett D. , "Help for Everyone....But Particular the Little Guy"; not published

2. AMT, The Economic Handbook of the Machine Tool Industry, Association of Manufacturing Technology, 1994-1995, p F-6

3. AMT, "Management Handbook for Quality Systems Development: In Machine Tool and Other Related Industries", The Association for Manufacturing Technology, November 1990 

